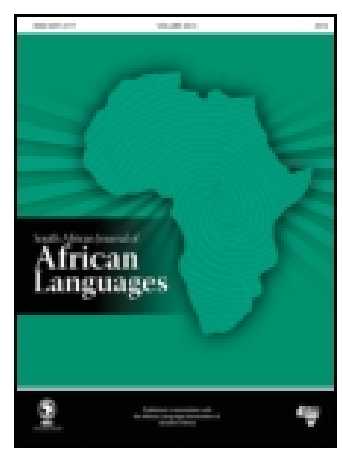

South African Journal of African Languages

\title{
Beyond 2000: Sharpening the focus on the indigenous languages
}

\section{Abner Nyamende}

To cite this article: Abner Nyamende (2008) Beyond 2000: Sharpening the focus on the indigenous languages, South African Journal of African Languages, 28:2, 126-132

To link to this article: http://dx.doi.org/10.1080/02572117.2008.10587308

曲 Published online: 24 Oct 2012.

Submit your article to this journal $\llbracket$

Џ Article views: 12

Q View related articles $\sqsubset$ 


\title{
Beyond 2000: Sharpening the focus on the indigenous languages
}

\author{
Abner Nyamende \\ Department of African Languages, University of Cape Town \\ Rondebosch 7701, South Africa \\ abner.nyamende@uct.ac.za
}

\begin{abstract}
This article is intended to stimulate intense discussions on the issue of the indigenous languages in South Africa. The Constitution of the Republic of South Africa stipulates that the South African indigenous languages are historically disadvantaged, and therefore extra effort should be applied to elevate their status and to advance their usage. The Bill of Rights stipulates that everyone has a right to use the language of his/her choice. This, therefore, means that the development of the indigenous languages is fully backed by our country's constitution. The Pan South African Language Board has given us correct guidelines towards developing our indigenous languages. In developing our indigenous languages we should observe language ownership, language diffusion and language empowerment.
\end{abstract}

\section{Introduction}

This article is intended to stimulate intense discussions on the issue of the indigenous languages by academics and researchers. Its point of departure is a language debate about the future of indigenous languages that took place in the $19^{\text {th }}$ century. From there the article illustrates how the scenario has unfolded up to the present moment. The author then looks at the role of the Pan South African Language Board, laying more emphasis on the vision, objectives and functions of this body. Finally, there is a discussion on the language expectations in South Africa and how far these expectations could take us. The conclusion consists of tentative suggestions about what could possibly be done to ensure a place for the indigenous languages in South Africa.

\section{Pride in indigenous languages}

As we enter the twenty-first century, it is essential to ensure that we bring our languages with us; the languages that have, for many generations of dire social distress, borne our culture: our customs, rituals, history, beliefs, etc. But, in addition, we need to examine the pride (or absence thereof) with which we talk about these languages. In July 1891 (Imvo, 1891.07.16), Isaac Wauchope Citashe wrote an article titled, 'The Kafir Language', which reflects much pride in his very rich subject: his own language. His sense of pride is embodied in the one brief expression in another article written on 23 July of the same year:

For my own part I would rather sacrifice a grand English style for a simple unextorted vernacular Kafir such as can only be attained by a careful study of the use of Kafir words or, in other words the study of Kafir composition and grammar (Imvo, 1891.07.23:3).

The above statement by Wauchope or Citashe (or Dyoba) is written in good English by a fine former student of Lovedale, who has no problem expressing himself in English as well as Dutch. Wauchope was one of the first black missionaries who took his mission to present day Malawi in 1876. The language debate that was held in 1891 by the South African black elite, who were graduates from the first seminary schools, demonstrated that these schooled people were quite at home in the use of English. Nevertheless, Wauchope expresses his unreserved pride in his home language.

Wauchope's debate addressed the question: 'Whether the study of Kafir Composition and Grammar should be made compulsory at Native Institutions?' (Imvo, 1891.07.23:3). It is interesting to note that, as far back as 1891, the educationists of that time were debating whether to make the study of indigenous languages compulsory. Wauchope further explains: 
As to the word 'compulsory', which seems to be objectionable even to those who are generally in favour of the subject being left to the option of each student, I don't think it means, in the present case, that unless Kafir Composition and Grammar were taught to all the pupils the Government grant would be withdrawn. All I mean at present is that no certificates - Government or University - should be granted to those Native students who shall not have passed in Kafir Grammar and Composition. This, in fact, is the pivot round which the whole question revolves; because the range of subjects taught in our Institutions is virtually determined by conditions laid down by Government, either for issuing grants or granting passes, and these conditions have been fixed with due consideration for the wants of those for whose benefit the schools exist (Imvo, 1891.07.16).

In today's language the term 'compulsory' would be replaced by 'language requirement' and 'government grant' would be replaced by 'subsidy to institutions of higher learning'. This debate about the need to study isiXhosa at school in 1891 suddenly finds relevance in the need to teach in indigenous languages in some of today's institutions.

Today, many schooled people associate the indigenous languages with illiteracy, ignorance and backwardness, and are often ashamed to identify themselves with these languages. A letter by M.W. Jadezweni that was published in the Cape Argus of 3 July 2001 (p.15), was quite refreshing in that it reflected the same sentiments about language as demonstrated by Wauchope. In his letter, Jadezweni concluded: 'Xhosa people neglect their own language. Such opportunism is immoral. I am very proud of my language isiXhosa'. Not much, however, comes from people who are not language practitioners and teachers. It would benefit us to quote some more from Wauchope's powerful article whose premise is: 'Whether the study of Kafir Composition and Grammar should be made compulsory at Native Institutions? ' He concedes:

I used myself to think the Kafir language was very simple, and that it would be throwing precious time away to study it. In fact I even boasted of being a pretty good Kafir speaker, but when it came to consecutive thinking and close arguing I found out my mistake, and applied myself to the study of my own language, comparing it with the other languages I had to study. How far I have been successful others can judge best, but I still feel that I do not know my own language yet (Imvo, 1891.07.16:3).

What was the scenario in Wauchope's time? The missionaries had brought the Western school system to the indigenous people of South Africa. Converting to Christian beliefs was the fashionable thing to do among the black people, and people such as Wauchope, who were born into a Christian home by parents who were already Christians by 1852, were seen as models of the future generation. They spoke polished English and a few of them also spoke Dutch, wore tailored coats and could eat with forks and knives. Being able to communicate only in indigenous languages was a sign of being unschooled, illiterate and backward. Requiring an interpreter was another strong signal of having these shortcomings.

\section{Language ownership}

I believe that today, the majority of South Africans would find nothing archaic about Wauchope's statement as quoted above. If it were applied in today's socio-political situation in South Africa, people would hardly find fault with the statement: 'I found out my mistake, and applied myself to the study of my own language, comparing it with the other languages I had to study'. The idea of 'my' vis-à-vis the 'other' people's languages in the same country is so much part of our culture of separate development that we can hardly recognize it in Wauchope's comment. Similarly, we often fail to appreciate one of the most precious differences between our Constitution and those of other countries, which is that our Constitution recognizes multilingualism as a bench mark of being truly South African, whereas in other countries the otherness of languages belonging to different communities is emphasized.

This brings us to the question: what is the scenario in South Africa at the present moment? It appears that things have grown worse since Wauchope's time. What used to be fashionable in his time is now a tradition, and so much 
part of our culture and personalities that we easily identify with amaXhosa, amaZulu, etc, as 'our languages', 'home languages', 'mother tongues', while we perceive other languages around our so-called 'mother tongues', as 'the other languages'. For example, an isiXhosa speaker sees isiXhosa as his solitary home language, while he views Xitsonga, Tshivenda, etc. as the 'other' South African languages.

A study of the various publications of the Pan South African Language Board (PanSALB) was made with the aim of extracting the vision of our government and our people about all the languages of this country, and particularly about the indigenous languages. Here this vision is being aligned with what I think would be the ideal situation regarding South African languages in the $21^{\text {st }}$ century. Our Constitution is acclaimed as one of the best constitutions in the world today, and it is unequivocal about the role of languages in the transformation of our society. PanSALB in its document, PanSALB's Position on the Promotion of Multilingualism in South Africa: a Draft Discussion Document, states:

South Africa is in a particularly unusual position in that it has more official languages at a national level than any other country. The Constitution obliges government to effect this official status and use and the Board to promote respect for other languages as well as to promote multilingualism and the development of languages in general. This obligation places South Africa at the cutting edge of international language policy development, which presents an exciting opportunity for breaking a new ground internationally (PanSALB, 1998:7).

Section 6 of the Constitution is wholly devoted to the languages of this country and Sub-Section (2) stipulates:

Recognising the historically diminished use and status of indigenous languages of our people, the state must take practical and positive measures to elevate the status and advance the use of these languages.

It appears, therefore, that there is a definite desire on the part of the people of South Africa to place the indigenous languages at the centre of the process of change and growth. There is a definite vision, and the vision seems to be quite unpretentious. All that is left is to create space for a foundation to be set and for a process of growth to begin. I regard Section 30 of the Bill of Rights in our Constitution (1996) as being the most central premise for any language expert and language user. It reads as follows:

Everyone has the right to use the language and to participate in the cultural life of their choice.

\section{Multilingualism and the individual}

This brings us to the issue of mother tongue and other tongues. The above section places all the languages and cultures of this country squarely in our lap, so that where we used to have only our community's language and culture to identify with, we now find ourselves with an inheritance of many languages and cultures, an inheritance so large that we find it hard to grasp. I truly admire the insight of the first members of PanSALB that has materialized in the operational structures they have created. I am particularly impressed by the openness with which PanSALB has approached the delicate issue of a multilingual inheritance. PanSALB has given much publicity to its vision and mission statement, but it would be apt to quote them at this stage, so that we are clear about the aspirations of this Board where the future of languages is concerned. The PanSALB vision is:

To provide for the recognition, implementation and furtherance of multilingualism in the Republic of South Africa through the development of previously marginalised languages. (www.pansalb.org.za/English/vision.htm).

The Board's mission statement says: 
The purpose of the Pan South African Language Board is to promote multilingualism in South Africa by:

- creating the conditions for the development of and the equal use of all official languages

- fostering respect for and encouraging the use of other languages in the country

- encouraging the best use of the country's linguistic resources

in order to enable South Africans to free themselves from all forms of linguistic discrimination, domination and division, and to enable them to exercise appropriate linguistic choices for their own well-being as well as for national development.

(www.pansalb.org.za/English/mission.htm).

A good thing about this vision and mission statement is that PanSALB has created a conceptual field around the issue of multilingualism to aid all involved to have a clear understanding of this term and its implications. In its document on multilingualism, PanSALB quotes Ingrid Gogolin (1993), who refers to:

the monolingual habitus in which the general, Western perception about language resides. The political, economic and military success of the West has resulted in a superimposing of the monolingual habitus upon the multilingual countries it subjugated. The multilingual reality which PANSALB is tasked with addressing needs to be understood against the overwhelming drive toward the monolingual habitus, and the dynamics of linguicism (PanSALB, 1998:7).

PanSALB observes that South Africa:

like most countries, is multilingual, which means that many languages are used in the country in various contexts and for various purposes. Most people are able to use more than one language; many people are able to use several languages (PanSALB, 1998:7).

It appears that the then Chief Executive Officer of the Language Board, Professor C.N. Marivate, clearly perceived the enormity of the responsibility laid in the hands of PanSALB when she said:

The recognition, implementation, and furtherance of multilingualism: that is what we hope to achieve. That is what we envisage we will have done when we say we have reached the ideal. Recognition of multilingualism, implementation of multilingualism, furtherance of multilingualism. An ideal. Will it ever be achieved? Yes, I think it will. When what was outlined in our mission has been carried out properly and effectively, we will have realised our vision (PanSALB, 2001:51).

This desire by Professor Marivate for an ideal of multilingualism generates another ideal, namely, that of the ideal South African citizen of the future, black or white. One has the picture of an individual who can use many of our languages as a natural activity, moving from one language to another as the situation dictates without suffering any strain or exhibiting melodrama. That should be the ideal South African citizen of the $21^{\text {st }}$ century. What should be done to reach this ideal?

\section{Laying the foundation for a multilingual society}

First of all, it is important to note that while there already is a small percentage of people who speak these South African languages as comfortably as their first language, the majority of our generation has not achieved such success. We should lay down the foundation towards realizing this goal in the lives of the coming generations. We must accept that we are a diseased generation, that the impediments of the apartheid culture which nurtured us in the tender years of our lives will always be with us in everything we do, and if we are not vigilant enough, it will crop up at odd moments, damaging or even ruining our delicate process of reconstruction. We must be constantly aware of our own shortcomings. Herein lies the irony of a society with flawed personalities, trying to construct a perfect future for themselves and their languages. 
Three aspects need highlighting as the central factors in ensuring a successful language plan towards multilingualism in South Africa in the $21^{\text {st }}$ century. These are: language ownership, language diffusion and language empowerment.

\section{Language ownership}

This aspect represents what we all need to learn and come to terms with. As already indicated, Section 30 of our Constitution (1996) places an inheritance of all our languages in our laps. What is left, is that we demonstrate that we are worthy of such a heritage. There should be a process whereby we come to terms with our inheritance, acknowledging its value and significance. The tendency, borne of our discriminatory judgement, is to reject our inheritance, picking out only the portion of it that we are used to. How many claim: 'These languages are all my personal inheritance' and yet inwardly they resist accepting those languages that they cannot speak as part of their lives, adhering, instead, to the former apartheid stereotypes as the only thing meaningful to them in this scenario? We need a programme to educate us about what it means to say, 'Everyone has the right to use the language ... of his/her choice'.

To effect education on language ownership, we need a user-friendly support structure. What we have at hand is PanSALB's organogram, with the Provincial Language Committees (PLCs) tasked with the function of advising the Board on language matters. Then there are the National Language Boards (NLBs), which represent the various languages of the country. All is well - we have a sound framework to support the process of change and development of the indigenous languages. But the question of ownership is still not fully addressed. At a workshop in 1999 (PanSALB, Record of the Provincial Language Committees Workshop, 2001), Advocate Christa Roodt explained to the PLCs that, 'PLCs consist of representatives of the South African languages used in the province proportionate to the language composition of the province as far as is practically possible' (italics mine). For practical reasons, this is quite good. All such a structure lacks is a permanent base that can be set, to help us to start turning the wheels towards the ultimate goal of multilingualism in the coming generations in South Africa, and we understand that this is the goal that the PanSALB has set itself.

Perhaps inadvertently, in the PanSALB structure, we see the vestiges of a deformed personality exhibited by this body. As they are, the PLCs are virtually nothing but a reminder of the past, for example, in the Eastern Cape the PLC would only have Xhosa, English and Afrikaans speaking members representing the old apartheid compartments. On the other hand, English and Afrikaans permeate the whole country and are represented in all the PLCs, while the other languages are represented only in one, two or three provinces. The end result is that an isiXhosa speaker, for example, represents isiXhosa in a PLC area of influence where the majority of speakers are amaXhosa. How different is that from having an isiXhosa speaking territory, a Tshivenda speaking territory, a Xitsonga speaking territory, as in the past?

For me, the ideal situation would be for a PLC to have eleven members representing the eleven official languages as the basic number of members. The number could then be increased according to the dominance of certain languages in a province combined with representation from the relevant areas of influence in the community. A structure like this would ensure that each province finds itself in possession of at least the official languages of the country. In that way, Section 30 of the Constitution would have been addressed, and a firm base would have been laid for the growth of all the indigenous languages on an equal basis. How a PLC addresses languages that did not traditionally belong to that region would be left to it and the individual who is responsible for the language. One would find that some PLCs would import representatives of the languages they did not traditionally have from the areas where those languages are concentrated. A PLC could also choose to leave language portfolios vacant if they feel that their province did not wish to exercise its ownership of that language. This brings us to the second aspect that is necessary to ensure multilingualism in the future of the languages of this country, namely language diffusion. 


\section{Language diffusion}

Presently, the indigenous languages are concentrated in certain areas of their traditional existence and only English and Afrikaans are used everywhere. How do we make the languages, which we all own equally, available to all of us so that we can use them as we wish? If a white South African in Cape Town wishes his/her children to use Xitsonga, Tshivenda and Sesotho in addition to English and perhaps French, will that person have facilities at hand to ensure that that happens? The first requirement would be for these languages to be available in some of the schools in the various communities.

It would not cost the Department of Education very much to have a sprinkling of teachers from the areas where certain languages are concentrated, teaching those languages in the various schools and communities. Soweto would be an ideal place for various schools to offer different indigenous languages. This is something that is quite practical. Speakers of the various languages could be identified, e.g. Tshivenda speakers in Mthatha, a predominantly isiXhosa speaking community, and language development programmes in which they are involved, may be designed.

Regrettably, the PanSALB does not seem to have considered language diffusion, a process that would aid the accessibility of all our languages to everyone, in fulfilment of the ownership principle.

\section{Language empowerment}

The third aspect is language empowerment. Who is going to waste time on a language that has no economic power? The traditional speakers of these languages have no money to plough into the development of the indigenous languages in the form of bursaries, research grants and commissioned publications. Our students ask us what they will do with these languages if they major in them. All we can do is mumble something about translation and interpreting. Publishing is still in the hands of people who also need to be educated on the meaning of multilingualism. How do we place these languages to where there is economic power, so that they can be as fully empowered as the English language? Some of us are watching the Department of Education closely to see if it will finally gather enough courage to implement the desire to teach in all the official languages of the country.

We will continue to learn to speak English, French and Portuguese because they are international languages. But, the majority of us only wish to live a good life here at home before we can think about international matters. We do not all want to trade overseas. There will always be those who do - they exist in all countries, even in the monolingual countries - but the majority will always want to live and work at home. There is no reason at this time and age for me to learn English first, if I can be trained through the medium of isiXhosa to be a radio technician.

The language policy for higher education, which has now been in existence for a couple of years, should bring multilingualism to tertiary education. But that is the subject for another article. At South African universities, the indigenous languages are clubbed together under one department, while English and Afrikaans continue to enjoy the status of being free-standing departments.

We should design a structure that is rooted in industry and business. Furthermore, our structures for implementing multilingualism must be rooted in all the communities of this country. PanSALB with its sub-structures, the PLCs, NLBs and National Language Units (NLUs), is to me just a surface structure that can barely have a direct influence on the individual in a community. What will happen is that the members involved in these structures will decide for the ordinary South Africans, while the person who possesses the language is the individual South African and not an expert or committee member. It would, therefore be imperative to have a structure whose roots are in industry, in the business world, as well as in the communities, for instance grassroots language committees in established organizations, business, on the factory floor, and churches. Some organizations, such as businesses with less than ten 
employees, could have just one language person. These could be serviced by the PLCs through a process involving workshops, talkshops, reports, etc. In that way, everyone in South Africa would experience the process of language transformation in the immediate environment. Surely, something can be done to stimulate industry and the business world into having their own language committees or people? And we should make sure that business and the industrial world are involved, because that is where economic power rests.

During an investigation to find out whether a concerted effort to effect genuine social transformation exists in this country, I found that for most provinces the process of formulating legal guidelines and strategies is still under way. But I think that the focus that we have been given by PanSALB is sufficient to get us to lay down the groundwork. While we accept that its 'explicit role is to create the conditions for the development of and equal use of all official languages' (PanSALB, 1998:3), we should go beyond this and cater for all our languages.

\section{Conclusion}

In conclusion, the indigenous languages will play a central role in the $21^{\text {st }}$ century if we lay a proper foundation, now that we have a focus. How can that happen if the universities that are the centres of learning and research are closing down the departments of African languages? While looking at the cases that PanSALB has handled (Annual Report, 2000) regarding the violations of language rights, I found one complaint about the discontinuation of Indian languages at the erstwhile University of Durban-Westville. I could not find any complaint against any threat or decision to reduce or close down an indigenous language department; a decision that I regard as an insult to the people of South Africa (PanSALB, Annual Report, 2000:55).

In 1891 Wauchope suggested the following:

All I mean at present is that no certificates - Government or University - should be granted to those Native students who shall not have passed in Kafir Grammar and Composition. This, in fact is the pivot round which the whole question revolves; because the range of subjects taught in our Institutions is virtually determined by conditions laid down by Government, either for issuing grants or granting passes, and these conditions have been fixed with due consideration for the wants of those for whose benefit the schools exist (Imvo, 1891.07.16).

Bringing Wauchope's argument to our times, I strongly suggest that matters such as subsidies for universities, should include the issue of how these universities are promoting the indigenous languages. In this way, we could ensure that the future of the indigenous languages in the $21^{\text {st }}$ century is indeed in our hands.

\section{References}

Cape Argus, 3 July 2001.

Imvo, 16 July 1891.

Imvo, 23 July 1891.

PanSALB in 'PanSALB's position on the promotion of multilingualism in South Africa: a draft document', 1998.

PanSALB Annual Report, June 2000.

PanSALB in Record of the Provincial Language Committees Workshop, 2001.

The Constitution of the Republic of South Africa, 1996.

www.pansalb.org.za/English/mission.htm Accessed on 2001/05/20.

www.pansalb.org.za/English/vision.htm Accessed on 2001/05/20. 